\title{
Influence of Morphemic Analysis on Vocabulary Learning Among Palestinian 10th Graders
}

\section{Mahmoud J. Itmeizeh ${ }^{1}$}

\author{
* Correspondence: \\ mitmeizeh@paluniv.edu.ps \\ ${ }^{1}$ Palestine Ahliya University College, \\ Bethlehem, Palestine
}

Received: 5 November 2017

Accepted: 15 January 2018

Published online: 20 June 2018

\begin{abstract}
The aim of this study is to identify the influence of morphological analysis strategy employed by Palestinian $10^{\text {th }}$ grade-female students in guessing and manipulating complex words in addition to using these words in meaningful sentences. This study involved 75 female students from Idna Secondary School for Girls at Hebron governorate. The sample of the study was assigned to control group (37 students) and experimental group (38 students) from two different sections. To achieve the aims of the study, morphological structure test based on students' textbook has been given to both groups in form of pretest/posttest. Meanwhile, the experimental group has received treatments on morphological analysis strategy prior to the post-test, whereas the control group hasn't received any treatment except for the traditional way of teaching for the same two units. Results showed that the experimental group has outperformed the control group as they scored higher grades. They also scored better results in identifying the syntactic category of English words depending used in context.
\end{abstract}

Keywords: morphological analysis strategy, morphological structure test, Palestinian 10th graders 


\section{Introduction}

Vocabulary plays a paramount importance in the process of teaching and learning languages. The English language is universal nowadays since it's not only the language of science and technology in most of countries, but it is also widely used for communication among all people all over the world. In the Palestine, students keep learning English for 8-12 years and when they use the communicative language, they show significant weakness. Palestinian students are not exceptional since we feel every day that our students have a great shortage in vocabulary repertoire. This hinders their ability to use the language communicatively. Consequently, this study aims to enhance vocabulary learning through morphological analysis strategy that may bring about autonomous learners who depend on themselves to find meanings of unknown words rather than depending on their teachers.

According to Bear et al. (2008) and Alderson and Banerjee (2002), vocabulary growth is a clear sign of how appropriately students can master the four skills of English language mainly the productive ones. They also argued that showing significant growth in learning vocabulary is so crucial for students so that they can comprehend and then use the language communicatively. It's worth mentioning in this context that equipping students with skills needed for gaining more independency in learning than being spoon-fed all the time. Therefore, more concentration on learning strategies should be the trend at schools and universities these days. In this study, the focus will be on the morphological analysis strategy that is hoped to help students acquire and then master the new vocabulary items in context depending on themselves.

Kuo and Anderson (2006) defined morphological analysis as the ability to use the knowledge of word formation rules and the pairings between sounds and meanings. Learners can acquire new words by segmenting words into morphemes. In this study, students learn the meaning of each morpheme and whether this morpheme is bound/free or lexical/grammatical one. They also study the meaning of each of these morphemes and how they are combined together to form complex words. Through this strategy, students will be able to reduce complex words into simple ones and categorize morphemes into prefixes, suffixes, and roots. Disassembling and reassembling morphemes into meaningful parts based on morphological analysis (e.g. the word naturalization), students are supposed to analyze this word into morphemes such as nature, natural (nature+al), naturalize (nature $+\mathrm{al}+\mathrm{ize}$ ) and naturalization (nature $+\mathrm{al}+\mathrm{ize}+$ ation). Through this strategy, students are also required to know the meaning of each of these morphemes.

According to Daniel (2014), Morphological Analysis (MA) is a strategy that helps students learn vocabulary by parsing words for familiar morphemes to infer the word's meaning. In this study, the researcher chose unit 2 and 3 of the English for Palestine, $10^{\text {th }}$ grade. All complex words were selected to be analyzed into morphemes with their meanings. So students learnt how to distinguish between free and bound morphemes in addition to the difference between derivational and inflectional ones. All suffixes and prefixes incorporated into these words were discussed to students focusing on meaning and function. Ample examples were given to students to show them how some affixes bring about a change in word class. Therefore, this study has a great focus on 
the internal structure of words. It also highlights the importance of studying the role of these morphemes in deriving or creating new words with a minor or a major change.

\section{Literature Review}

This section elaborates the theoretical background of the study in addition to some up-to-date related studies conducted by other researchers.

\subsection{Theoretical Background}

Vermeer (2001) and Zimmerman (2005) stated that there is a strong relationship between a person's vocabulary size and their language proficiency because words are the primary carriers of meaning. Therefore, if students have a shortage in the number of vocabulary items, they won't be able communicate efficiently to express their thoughts. When they encounter morphologically complex words while reading texts, students can use morphemic analysis strategy to decode the meaning (Bellomo, 2009). Being able to break down morphologically complex words into the smallest segments or morphemes (prefixes, suffixes, and roots), students will show significant advancement in finding meanings of new words independently with no help from the teacher.

Kieffer and Lesaux (2007) assured that as students leave primary stage to secondary stage, they face more and more sophisticated texts as they include difficult complex words. So teachers should introduce students to more innovative learning strategies to study new vocabulary. Both studies of Baumann et al. (2003) assured that when students are more aware of the complex words morphemes, they can learn more vocabulary items and comprehend the assigned text. On the other hand, Biemiller and Boote (2006) assert that morphemic analysis is a highly crucial learning strategy for promoting vocabulary repertoire.

\subsection{Related Studies}

Khoshkhoonejad et al. (2016) conducted a study that aims at investigating the effect of morphological instructions on vocabulary learning among Iranian secondary school students. 60 Iranian students constitute the sample of the study. The researcher divided students into two groups: control group (30) and experimental group (30). A pre-test and post-test comprising two vocabulary tests measuring students' morphemic analysis of general English words were administered. Results showed that the experimental group outperformed the control group in the process of guessing the meanings of complex words depending on the morphological analysis.

Chandrakala Varatharajoo et al. (2015) had a research to investigate the effectiveness of morphemic analysis awareness on ESL secondary school students' vocabulary acquisition. 100 ESL secondary school students were divided into two groups: an experimental group and a control group. The instruments of the study were Morph-Analysis Test and Morph-Vocabulary Test. They were used as pre-test and post-test. Results revealed that the experimental group achieved a significant score in Morph-Analysis Test and Vocabulary-Morphemic Test. 
Paiman et al. (2015) explained the effects of morphemic analysis of Graeco-Latin roots and affixes as a vocabulary learning strategy among Malaysian ESL learners. Three classes of undergraduates majoring in health sciences were divided into three different treatments which are instructions focusing on Graeco-Latin morphemic analysis, general morphemic analysis, and use of contextual clues as vocabulary learning strategies. Participants in all groups underwent the instructional intervention twice a week for a five-week period. Each group was taught how to derive word meanings using these three different strategies. The findings of the study showed that (a) the group taught Graeco-Latin morphemic analysis scored the highest in all three vocabulary measures, (b) the group taught general morphemic analysis also improved in morphemic analysis of general English words but not Graeco-Latin words and improved slightly in overall vocabulary size.

Taha et al. (2015) conducted a study that aims at identifying the effectiveness of morphological analysis strategy employed by Iraqi secondary school students in guessing and manipulating complex words and also to determine which one of the two strategies (Morphological Relatedness \& Morphological Structure) is more effective. The sample of the study constitutes 40 subjects distributed into a control group and an experimental group, 20 for each. To achieve the purpose of the study, Morphological Relatedness Test and Morphological Structure Test, adapted from Curinga (2014), were given to both groups in the form of pre-test and with no significant differences between both groups. Meanwhile, the experimental group received two treatments on morphological analysis strategy prior to post-test, whereas control group did not receive any treatment. Finally, both groups took a post-test with the same tool and the results showed that the experimental group outperformed the control group in the process of guessing the meanings of complex words depending on the morphological analysis.

Rebecca Curinga (2014) tests the effectiveness of morphological awareness in reading comprehension of high school growing bilinguals. The sample is newcomer Spanish-speaking high school students. The main research question examines the effect of morphological awareness on reading comprehension in the L1 Spanish, in the L2 English, and across these languages. Results showed that morphological awareness makes a strong contribution to reading comprehension in both the L1 Spanish and L2 English; and the shared contribution of morphological awareness and reading vocabulary of these two predictors together is strongest.

\section{Significance of the Study}

Varatharajoo et al. (2015) stated that many studies showed that morphological structure tests are so effective in vocabulary enhancement. To the best of the researchers' knowledge, very little research, if any, has been conducted on the Palestinian primary or secondary school students using the morphological strategies to improve students' ability in discovering the meanings of unknown vocabulary items. Therefore, this study is undertaken to address the issue and bridge the gap in literature. So, it might be of great benefit to both teachers, students, and even the decision makers who may conduct a genuine measures for the sake of developing students' proficiency. Students can easily find out meaning of complex words through analyzing them into smaller segments. 
Teachers can also be more aware of new teaching and learning strategies that enhance students' proficiency of learning new vocabulary items needed for successful communication.

\section{Methodology}

The frame of this research is built on morphemic analysis strategy. Complex words are made of morphemes and morphemes are the smallest unit of a language; thus students can acquire vocabulary from two main ways. First, they can decode word meanings by disassembling complex words into meaningful morphemes. Second, morphemes can also be used to derive the meaning of complex words. When students are able to identify the suffixes, prefixes, and bases in addition to their meanings, they can support their understanding of morphologically complex words. This study was an experimental pre-test-treatment-post-test design with one control group and one experimental group done in the Palestinian EFL context. The research was set at a female secondary school in rural setting, Palestine. 75 female students from two classes of one school were involved in this study. Group $1(n=37)$ as the control group and group $2(n=38)$ as an experimental group was chosen accordingly. This study was conducted in Spring, 2017.

\subsection{Instruments}

To answer the present study's questions of the effect of morphological analysis strategy on vocabulary learning among Palestinian female $10^{\text {th }}$ grade students, a pre-post-test was the instrument applied to achieve the purpose of the study. The Morphological Structure Test (Appendix 1) was employed to measure the respondents' ability in analyzing complex words to create new words. Curinga (2014) asserted that this test is important since it can measure students' manipulation ability in identifying and constructing new words. The respondents were asked to construct the word that best matches the sentence (for example, care in the sentence: My sister is very careless). The test was composed of 45 items concerning derivational and inflectional affixes.

\subsection{Participants}

The population from which the subjects of the present study are selected includes 75 female $10^{\text {th }}$ graders from Idna Secondary School for Girls. It is worth mentioning that Idna is about 15 Kilometers to the west of Hebron. The EFL students in this school have been learning English language for 10 years. The first language of all of the students is Arabic. In order to make the participants as homogenous as possible, the researcher studies the students' grades reports in the $9^{\text {th }}$ grade. Then two sections out of four were chosen as they have nearly the same grades in the $9^{\text {th }}$ grade. This homogeneity was assured by the results of the pre-test which were so close to a great extent. The mean age of the participants of the study is 15.7 years, with an age range of 15.5 to 16.2 and they are classified into two groups: experimental group and a control group.

\subsection{Validity of the Tools}

To ascertain the validity of the instrument, the Morphological Analysis Structure Test was given to expert jury who are specialized in the same field. Some items were modified and others were added to meet the recommendations of the experts. 


\subsection{Reliability of the Tools}

To ascertain the reliability of the test, Cronbach's alpha reliability indices were calculated for the tool of the study (Morphological Structure Test). The test was administered to a pilot sample other than those in the control and the experimental groups. The result of Cronbach's alpha was (0.91) as shown in Table 1. Therefore, the instrument can be considered to have a high reliability standard and good for classroom tests because the coefficient alpha is above 0.70 (Sekaran \& Bougie, 2010).

Table 1. Results of Cronbach's Alpha for the reliability of the Morphological Structure Test

\begin{tabular}{lcc}
\hline Instrument & No. of Items & Alpha \\
\hline Morphological Structure Test & 45 & 0.91 \\
\hline
\end{tabular}

\subsection{Design of the Study}

This section focuses of the research design of the study to logically integrate the whole components of the study so as to meticulously address the research problem. Hence, the statement of the problem, the aims of the study, and the questions of the study.

\subsubsection{Statement of the Problem}

In 2000, the Palestinian Ministry of Education determined to teach the English language from the $1^{\text {st }}$ grade as part of a program that aims to bring about a dramatic change in students' linguistic abilities. They targeted the four skills of English language. But the main focus was on listening and speaking and they gradually focus on the other two skills (reading and writing) as students' progress to higher grades. English for Palestine was used as a reaction to the use of the Jordanian curriculum (PETRA). However, after 17 years of implementing English for Palestine, students still suffer from serious weakness in all skills mainly the productive ones, speaking and writing. This may be attributed to many reasons, but the researcher believes that lack of focus on learning strategies compared to the great focus on methods of teaching can be considered one of the main sources of this weakness. Since vocabulary constitutes the building blocks of language and has an important role in language learning, many scholars have focused on the strategies of vocabulary teaching and learning (Kaweera, 2013). Therefore, the researcher decided to implement the morphological analysis strategy to enhance students' abilities in identifying meanings of words via breaking them into morphemes.

\subsubsection{Objectives of the Study}

The objective of this study is to investigate the effectiveness of morphological analysis strategy on developing students' vocabulary repertoire used in contexts. 


\subsubsection{Questions of the Study}

The study will attempt to answer the following questions:

1. Is there any statistically significant difference between the means of students' achievement in vocabulary learning for both control and experimental groups?

2. Is there any statistically significant difference between the means of the pre-test and posttest for both control and experimental groups?

\section{Data Collection Procedure}

The data collection was done in two phases: pre-test and post-test. In the first phase, the two groups took a pre-test (Morphological Structure Test) in order to see their performance in guessing the meanings of the new words depending on morphological analysis. The same test was administered as a post-test to investigate the students' improvement in vocabulary learning after they experienced morphological analysis for two months while studying the two units of $10^{\text {th }}$ grade, English for Palestine. After administering the pre-test, the experimental group was given a treatment on analyzing complex words (e.g. Unbelievable $=u n+$ believe + able) in addition to the meaning and function of each single morpheme, whereas the control group did not receive any treatment. Throughout the treatment, students were given base words and their classes, meanings of the these words, their suffixes, meanings of the suffixes, resulting words and their classes, meanings of the resulting words, and finally many examples of the resulting words are supplied by the teacher (Appendix 3). As the two-month treatment for experimental group was completed, both groups performed a post-test with the same tool (Morphological Structure Test) to see the effectiveness of the morphological analysis strategy on their vocabulary achievement.

\section{Analysis}

\subsection{Analysis of Research Questions}

In this section, the results of the study are presented and discussed through answering the two questions of the study. The pre-post-test scores for the Morphological Structure Test of the two groups are shown in Tables 1 and 2.

\subsubsection{Analysis of Question One}

Is there any statistically significant difference between the means of students' achievement in vocabulary learning for both control and experimental groups?

To answer this question, the researcher used paired sample t-test (Table 2) to find out whether the differences in means between students' scores of both groups are statistically significant or not. 
Table 2. Results of paired sample t-test

\begin{tabular}{lccccc}
\hline Group & No. & \multicolumn{2}{l}{ Mean } & Df & T value \\
& & & SD & & \\
\hline Control group & 37 & 14.19 & 3.04 & 73 & \\
Experimental group & 38 & 31.94 & & & 29.18 \\
\hline
\end{tabular}

As seen in the above table, there is a statistically significant difference between the means of students' achievement at ( $\alpha$ : 0.05) for the favor of the experimental group.

\subsubsection{Analysis of Question Two}

Is there any statistically significant difference between the means of the pre-test and post-test for both control and experimental groups?

To answer this question, the researcher used paired sample t-test (Table 3) to find out whether the differences between the means of pre-test/post-test for both groups are statistically significant or not.

Table 3. Results of paired sample t-test

\begin{tabular}{llccc}
\hline Group & Test & Mean & SD & T value \\
\hline Control group & Pretest & 5.58 & 2.32 & 15.55 \\
& Posttest & 14.19 & 3.04 & \\
\multirow{2}{*}{ Experimental group } & Pretest & 8.63 & 2.69 & 38.01 \\
& Posttest & 31.94 & 2.11 & \\
\hline
\end{tabular}

As seen in the above table, the absolute value of the test statistic is greater than the critical value, so there is a statistically significant difference between the means of students' achievement at ( $\alpha: 0.05)$ for the favor of the post-test scores for both groups. However, scores of the experimental group ( $M=31.94)$ in the post-test are significantly higher than that of the control group $(M=14.19)$.

\section{Discussion}

The aim of the study was to investigate the effectiveness of morphological analysis strategy on students' vocabulary learning. The present study showed that students' awareness of 
morphological analysis of complex words brings about a significant improvement in vocabulary learning and an increase in students' vocabulary repertoire. The pre-test was carried out by subjects prior to teaching students morphological analysis strategy of complex words. Therefore, both groups performed poorly in the pre-test which ascertain the homogeneity of students' level or proficiency. After the implementation of the pre-test, the experimental group was instructed the best ways of analyzing complex words into morphemes. The teacher also focused on teaching students the function and the meaning of each of these morphemes. Both groups performed well in the post-test. These results are also in harmony with that of Khoshkhoonejad et al. (2016) study, showing that the experimental group outperformed the control group in the process of guessing the meanings of complex words depending on the morphological analysis. Results of the study of Chandrakala Varatharajoo et al. (2015), Paiman et al. (2015), and Taha et al. (2015) also proved that students progressed significantly in vocabulary learning as a result of morphemic analysis.

Results also showed the importance of having our students more aware of the derivational and inflectional morphology so that they can identify and use vocabulary items appropriately for communicative purposes. Results of the experimental group in the post-test showed that students were more able to use the appropriate word class tailored for the context provided. Results of this study are in line with the study of Khodadoust et al. (2013) who claimed that students who have the ability to learn new words depending on the morphological structure analysis can boost their vocabulary repertoire. All in all, many researchers argue that the morphological awareness is of paramount importance for learners as it is correlated with vocabulary growth. Moreover, experimental learners who were exposed to lessons on morphological analysis strategy, performed much better than their classmates who were taught the same two units traditionally. Hence, the process of developing morphological awareness should be taken into consideration as it contributes to learners' vocabulary growth (Al Farsi, 2008). As indicated in tables above, the control group performed poorly compared to experimental group, this clear indication assures the urgent need to include clear instructions on morphological knowledge (Al Farsi, 2008).

\section{Conclusion}

Since the experimental group significantly outperformed the control group, this means that the traditional way of teaching complex words to students is greatly less effective than using the morphological analysis strategy. Analyzing words into smaller meaningful morphemes proved to be so effective in improving students' level in vocabulary learning and its use in meaningful sentences. It should be highlighted that teachers at schools need to introduce word formation processes to students. In this study, students showed significant improvement as they learnt more about affixation because they knew how to analyze words into minimal units. Most students became more aware of the internal structure of complex words through dividing them into prefixes, suffixes, and base (root). Based on the results of the study and the review of the literature, the researcher can claim that morphemic analysis, when it is introduced appropriately, brings about a dramatic change in students' level resulted from enriching the vocabulary repertoire of each student. To sum up, I think that teachers should emphasize the use of morphemic analysis of 
complex words wherever occurs so as to facilitate the process of vocabulary learning which may help students to store words in the long-term memory and rehearse them quickly and easily.

\section{Recommendations}

The study recommends future researchers to consider teaching morphological analysis to all students in all stages even in the university level especially when teaching the service courses. Future research should also focus on teaching more prefixes and suffixes in addition to their role in changing word class. The decision makers in the Palestinian Ministry of Education should initiate the journey of dramatic change in the curricula to be in harmony with the students' needs. It is of profoundly importance to have all vocabulary items taught through contexts. Moreover, students need language for communication not memorization that lacks students' ability for expressing their thoughts and ideas. Finally, the curricula should include some focus on the morphological analysis strategy to help students get the meaning of unknown complex words via dividing the words into morphemes.

\section{References}

Al Farsi, B. (2008). Morphological awareness and its relationship to vocabulary knowledge and morphological complexity among Omani EFL University students. Unpublished Master's Thesis, University of Queensland, St Lucia, Australia. https://espace.library.uq.edu.au/view/UQ:151557

Alderson, J. C., \& Banerjee, J. (2002). Language testing and assessment (Part 2). Language Teaching, 35(2), $79-113$. https://doi.org/10.1017/S0261444802001751

Baumann, J. F., Edwards, E. C., Boland, E. M., Olejnik, S., \& Kame’enui, E. J. (2003). Vocabulary tricks: Effects of instruction in morphology and context on fifth-grade students' ability to derive and infer word meanings. American Educational Research Journal, 40(2), 447-494. http://journals.sagepub.com/doi/abs/10.3102/00028312040002447

Bear, D. R., Invernizzi, M., Tempelton, S., \& Johnston, F. (2008). Words their way: Word study for phonics, vocabulary, and spelling instruction (4th edition). Upper Saddler River, NJ: Pearson Prentice Hall. https://www.pearson.com/us/higher-

Bellomo, T. S. (2009). Morphological analysis and vocabulary development: Critical criteria (p.45) http://www.readingmatrix.com/ articles/bellomo/article.pdf.

Biemiller, A., \& Boote, C. (2006). An effective method for building meaning vocabulary in primary grades. Journal of Educational Psychology, 98(1), 44. https://www.researchgate.net/publication/247410360

Curinga, R. (2014). The effect of morphological awareness on reading comprehension: A study with adolescent Spanish-English emergent bilinguals. CUNY Academic Works. http://academicworks.cuny.edu/gc_etds/30.

Kaweera, C. (2013). Writing error: A review of interlingual and intralingual interference in EFL context. English $\begin{array}{llll}\text { language teaching, } & 6(7), & \text { 9. } & \text { http://dx.doi.org/10.5539/elt.v6n7p9 }\end{array}$ http://www.ccsenet.org/journal/index.php/elt/article/view.

Kieffer, M. J., \& Lesaux, N. K. (2007). Breaking down words to build meaning: Morphology, vocabulary, and reading comprehension in the urban classroom. The reading Teacher, 61(2), 134144. https://eric.ed.gov/?id=EJ776395 
Khodadoust, E., Aliasin, S. H., \& Khosravi, R. (2013). The relationship between morphological awareness and receptive vocabulary knowledge of Iranian EFL learners. International Journal of Educational Research \& Technology, 4(1), 60-67. www.soeagra.com/ijert/ijertmarch2013/10.pdf

Khoshkhoonejad, A. A., Khalifelu, S. F., \& Abdipour. S. (2016). Exploring the effect of morphological instruction on vocabulary learning among Iranian EFL learners. Journal of Education and Learning, 10(2), 151-158. DOI: http://dx.doi.org/10.11591/edulearn.v10i2.3316

Kuo, L. J., \& Anderson, R. C. (2006). Morphological awareness and learning to read: A cross language perspective. Educational Psychologist, 41(3), 161-180. http://www.tandfonline.com/doi/abs/10.1207/s15326985ep4103_3

Paiman, N., Thai, Y. N., \& Yuit, G. M. (2015). Effectiveness of morphemic analysis of Graeco-Latin word parts as a vocabulary learning strategy among ESL learners. 3L: The Southeast Asian Journal of English Language Studies, 21(2), 31-45. https://scholar.google.com/scholar?

Roth, D. (2014). Morphological analysis as a vocabulary strategy in post-secondary reading: Literature review and annotated bibliography. Retrieved from https://grammarteaching.files.wordpress.com/2014/07/annotatedbibliography-on-morphological-analysis.pdf (accessed 02/02/2017).

Sekaran, U., \& Bougie, R. (2010). Research methods for business: A skill building approach (5th ed.). Haddington John Wiley \& Sons.

Taha, A., Amanj I., A., \& Mohamad, M. Y. (2015). The influence of morphological analysis on vocabulary learning among Iraqi secondary school students in Malaysia. International Journal of Education and Research, 3(5), 457. http://www.ijern.com/journal.

Varatharajoo, C., Asmawi, A. B., Abdallah, N., \& Abedalaziz, M. (2015). The awareness of morphemic knowledge for young adults' vocabulary learning. The Malaysian Online Journal of Educational Science, 3(2), 45-56. https://eric.ed.gov/?id=EJ1085913

Vermeer, A. (2001). Breadth and depth of vocabulary in relation to acquisition and frequency of input. Applied Psycholinguistics, 22, 2, 217-234. $\quad$ https://www.cambridge.org/core/journals/appliedpsycholinguistics/article/breadth-

Zimmerman, K. (2005). Newly placed versus continuing students: Comparing vocabulary size. ESL Reporter, 38(1), $52-60$. 


\section{Appendix 1}

\section{Test of Morphological Structure:}

Section A: Fill in the blank with the form of the word that best matches the sentence.

Example A: Help: My sister is very helpful.

Example B: Farm: My uncle is a farmer.

Example C: Dryer: The clothes need more time to Dry.

1- Arrange: They'd made all the for the party.

2- Energy: He's very , isn't he, for a man of his age?

3- Interest: She's got some very things to say on the subject.

4- Tradition: The dancers were wearing Palestinian dress.

5- Complete: I agree with you

6- Accept: This essay is not of an standard - do it again.

7- Colour: The town, of course, has a very history.

8- Miss: The letter eventually turned up inside a book.

9- Damage: They're selling off goods at reduced prices.

10- Appoint: I've got an to see Ms Edwards at two o'clock.

11-Invite: A lot of people have got their to the party but half of them didn't turn up.

12- Question: Visitors to the country have been asked to fill in a detailed

13-Danger: The men are armed and

14-Sudden: The door flew open.

15- Travel: can break their journey in Singapore if they wish.

16- Beauty: She dresses

17- Conversation: He seems to lack basic skills.

18- Organize: An by subject rather than by date seems to make sense.

19- Continuous: He spoke for more than two hours.

20- Act: Her younger son was killed in

21- Rearrange: There was a last-minute of the schedule.

22-Navigate: In the past, depended on a knowledge of the positions of the stars.

23- Connect: Two men have been arrested in with the theft. 
24- Use: Your advice was very , saving me a lot of time.

25- Danger: Whooping cough is most for infants.

26- Comfort: I'm not speaking in front of an audience.

27- Inform: Can you give us some on tours to Alaska?

28- Pronounce: There are two acceptable for the word "either."

29- Emphatic: $\mathrm{He}$ denied the rumors.

30- Describe: Your of Della was amusing.

\section{B. Identify the base form of the words given.}

31- Acceptable: She is too proud to any help.

32- Arrangement: I'm trying to my work so that I can have a couple of days off next week.

33- Agreement: I with you completely.

34- Missing: Often I breakfast and have an early lunch instead.

35- Damaged: Smoking is likely to your health permanently.

36- Colorful: What's your favorite $?$

37- Dangerous: He drove so fast that I really felt my life was in

38-Suddenly: He had a heart attack while he was on holiday.

39- Pronunciation: How do you your last name?

40- Organization: She has to her work so that she could do some of it at home.

41- Useful: Do you know how to a computer?

42- Comfortable: He's a great to his mother.

43- Strength: You need to be enough to pass this critical stage.

44-Informative: You should me about almost any new architectural design.

45- Reasonable: There is no why we shouldn't go shopping. 


\section{Appendix 2}

Answer Key of the "Test of Morphological Structure):

Section A: Fill in the blank with the form of the word that best matches the sentence.

Example A: Help: My sister is very helpful.

Example B: Farm: My uncle is a farmer.

Example C: Dryer: The clothes need more time to Dry.

1- Arrange: They'd made all the arrangements for the party.

2- Energy: He's very energetic, isn't he, for a man of his age?

3- Interest: She's got some very interesting things to say on the subject.

4- Tradition: The dancers were wearing traditional Palestinian dress.

5- Complete: I agree with you completely.

6- Accept: This essay is not of an acceptable standard - do it again.

7- Colour: The town, of course, has a very colourful history.

8- Miss: The missing letter eventually turned up inside a book.

9- Damage: They're selling off damaged goods at reduced prices.

10- Appoint: I've got an appointment to see Ms Edwards at two o'clock.

11- Invite: A lot of people have got their invitation to the party but half of them didn't turn up.

12- Question: Visitors to the country have been asked to fill in a detailed questionnaire.

13-Danger: The men are armed and dangerous.

14-Sudden: The door suddenly flew open.

15- Travel: Travellers can break their journey in Singapore if they wish.

16- Beauty: She dresses beautifully.

17- Conversation: He seems to lack basic conversational skills.

18- Organize: An organization by subject rather than by date seems to make sense.

19- Continuous: He spoke continuously for more than two hours.

20-Act: Her younger son was killed in action.

21-Rearrange: There was a last-minute rearrangement of the schedule.

22-Navigate: In the past, navigation depended on a knowledge of the positions of the stars.

23- Connect: Two men have been arrested in connection with the theft. 
24- Use: Your advice was very useful, saving me a lot of time.

25- Danger: Whooping cough is most dangerous for infants.

26- Comfort: I'm not comfortable speaking in front of an audience.

27- Inform: Can you give us some information on tours to Alaska?

28- Pronounce: There are two acceptable pronunciations for the word "either."

29- Emphatic: He emphatically denied the rumors.

30- Describe: Your description of Della was amusing.

\section{B. Identify the base form of the word given.}

31- Acceptable: She is too proud to accept any help.

32- Arrangement: I'm trying to arrange my work so that I can have a couple of days off next week.

33- Agreement: I agree with you completely.

34- Missing: Often I miss breakfast and have an early lunch instead.

35- Damaged: Smoking is likely to damage your health permanently.

36- Colorful: What's your favorite color?

37- Dangerous: He drove so fast that I really felt my life was in danger.

38- Suddenly: He had a sudden heart attack while he was on holiday.

39- Pronunciation: How do you pronounce your last name?

40- Organization: She has to organize her work so that she could do some of it at home.

41- Useful: Do you know how to use a computer?

42- Comfortable: He's a great comfort to his mother.

43-Strength: You need to be strong enough to pass this critical stage.

44- Informative: You should inform me about almost any new architectural design.

45- Reasonable: There is no reason why we shouldn't go shopping. 
Appendix 3

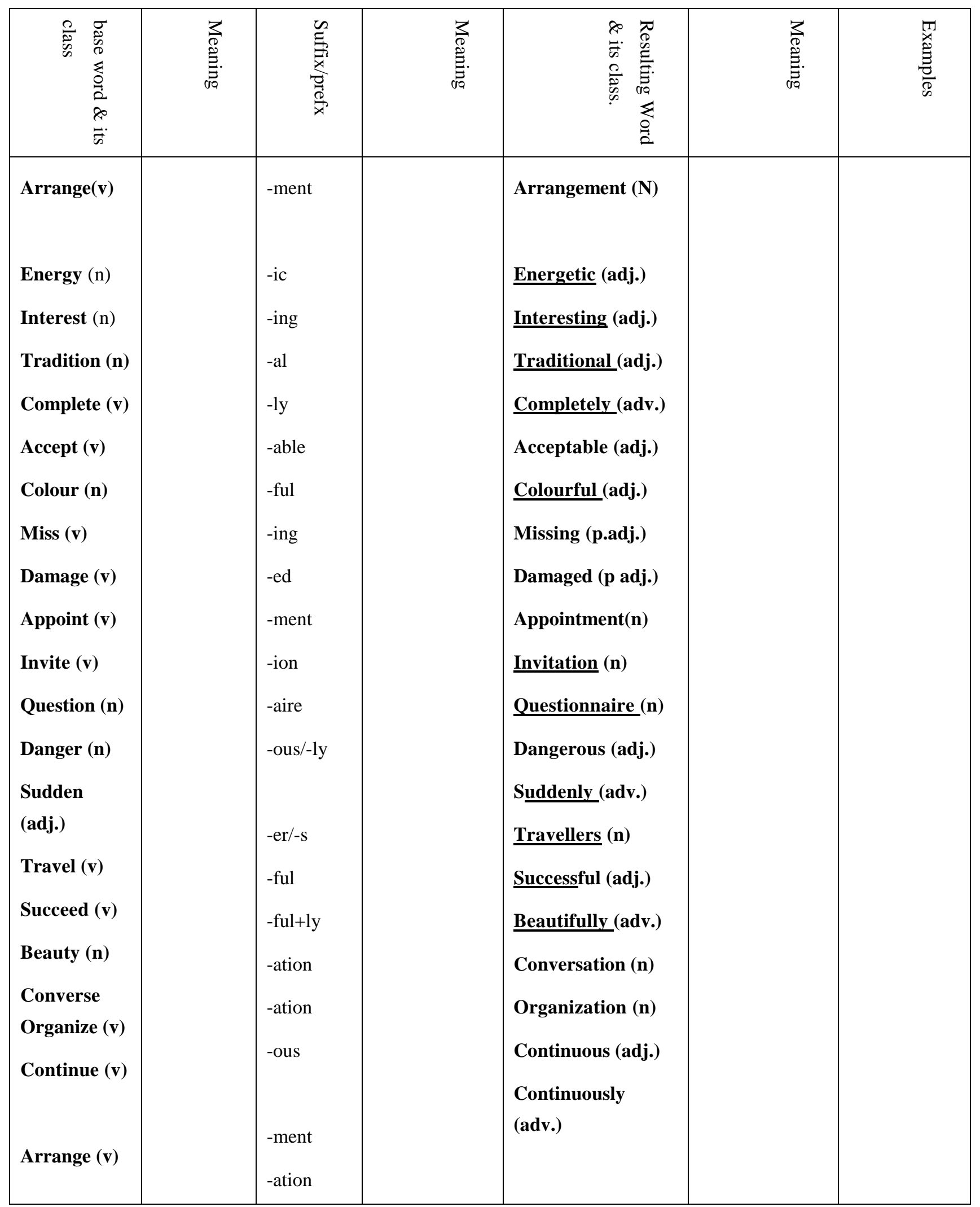




\begin{tabular}{|l|l|l|l|l|}
\hline Navigate (v) & - ion & Re/arrangement & \\
Connect (v) & - ful & (n) & \\
Use (v) & Navigation (n) & \\
Comfort (n) & -able & Connection (n) & \\
Inform (v) & -ation & Useful (adj.) & \\
Pronounce & -ation & Comfortable (adj.) & \\
(v) & -ic & Information (n) & \\
Emphasize(v & -tion & Pronunciation (n) & \\
) Describe (v) & & Emphatic (adj.) & \\
& & Description (n) & \\
\hline
\end{tabular}

Complex words taken from units two and three (English for Palestine, $10^{\text {th }}$ grade) 